\title{
PENENERAPAN PENDEKATAN REALISTIC MATHEMATIC EDUCATION UNTUK MENINGKATKAN KEMAMPUAN KOMUNIKASI MATEMATIK SISWA MTS
}

\author{
Novita Anggraini $^{1}$, Nur Indah Pertiwi ${ }^{2}$, M. Afrilianto $^{3}$ \\ 1,2,3 IKIP Siliwangi, Jln Terusan Jendral Sudirman. Cimahi \\ ${ }^{1}$ Novitaa231@gmail.com,2Nurindahpertiwi22@gmail.com ${ }^{3}$ \\ muhammadafrilianto1@ikipsiliwangi.ac.id
}

\begin{abstract}
The purpose of conducting research to examine the effect of the Realistic Mathematic Education (RME) Approach, on the achievement of MTs students' mathematical communication skills tests. The method used in this study is a quasi-experimental method. The population used was all students of MTs Nihayatul Amal, with each of the 20 selected samples from grades VII A and VII B. The instrument used a mathematical communication ability test that had been tested, a total of 6 items. The results show the mathematical communication skills of students in the experimental class are superior to the class with conventional learning.
\end{abstract}

Keywords: Mathematical Communication Skills, Realistic Mathematic Education (RME)

\begin{abstract}
Abstrak
Maksud diadakannya penelitian untuk mengkaji pengaruh Pendekatan Realistic Mathematic Education (RME), pada capaian tes kemampuan komunikasi matematik siswa MTs. Metode yang digunakan pada penelitian ini adalah metode kuasi eksperimen. Populasi yang digunakan merupakan seluruh siswa MTs Nihayatul Amal, dengan masing-masing 20 sampel terpilih dari kelas VII A dan VII B. Instrumen memakai tes kemampuan komunikasi matematik yang telah diujicoba, sejumlah 6 butir soal. Adapun hasilnya menunjukan kemampuan komunikasi matematik peserta didik pada kelas eksperimen lebih unggul ketimbang kelas dengan pembelajaran konvensional.
\end{abstract}

Kata Kunci: Kemampuan Komunikasi Matematis, Pendekatan Realistic Mathematics Education (RME)

How to cite: Anggraini, N., Pertiwi, N.I., \& Afrilianto, M. (2019). Penenerapan Pendekatan Realistics Mathematics Education Untuk Meningkatkan Kemampuan Komunikasi Matematik Siswa Mts. JPMI - Jurnal Pembelajaran Matematika Inovatif, 2 (5), 283-292.

\section{PENDAHULUAN}

Pendidikan adalah suatu proses pembelajaran pengetahuan, keterampilan serta kebiasaan seseorang yang diwariskan dengan mengembangkjan nilai-nilau budaya yang diturunkan dari satu generasi ke generasi berikutnya. Pendidikan adalah usaha sadar dan terencana untuk mewujudkan suasana belajar dan proses pembelajaran agar siswa aktif mengembangkan potensi dirinya nuntuk memiliki kekuatan spiritual keagamaan, pengendalian diri, kepribadian, kecerdasan, akhlak mulia, serta keterampilan yang diperlukan dirinya, masyarakat bangsa dan negara. Pembelajaran di sekolah memiliki fungsi sebagai proses pembentukan 
pribadi,penyiapan warga negara, penyiapan tenapa kerja dan sebagai proses transformasi budaya, Rohaeti (2011).

Tujuan utama pembelajaran matematika ialah agar siswa memiliki kemampuan matematik yang memadai untuk melambangkan kemampuan komunikasi dengan menggambarkan bilangan dan simbol dan mempertajam penalaran siswa dan menyelesaikan permasalahan dalam kehidupan sehari-hari. Kemamampuan matematik yang dimaksud mencakup pemecahan masalah, komunikasi, penalaran, dan representasi matematis, berpikir kritis dan kreatif, Tujuan yang disampaikan di atas telah tertuang dalam Permendiknas No. 22 tahun 2006 tentang Standar Isi Mata Mata Pelajaran Matematika, serta dalam beberapa kurikulum yang telah berlaku sebelumnya di Indonesia [1]. Akan tetapi, tujuan pembelajaran matematika telah dirumuskan dengan baik hingga saat ini masih belum tercapai. Beberapa hasil studi memperlihatkan bahwa kemampuan matematis siswa-siswa Indonesia belum berkembang secara optimal, seperti tergambar dari hasil The Trend in International of Mathematics and Science Studies (TIMSS) dan Program for International Student Assessment (PISA) Fauzan dan Yerizon (2013).

Komunikasi matematik merupakan salah satu kemampuan yang harus dimiliki siswa karena komunikasi merupakan bagian yang sangat penting pada proses pembelajaran matematika. Seperti dikemukakan oleh Greenes dan Schulman Sufi (2016) bahwa komunikasi matematik memiliki peran sebagai wadah bagi siswa dalam berkomunikasi dengan temannya untuk memperoleh informasi, membagi pemikiran dan penemuan, curah pendapat, menilai dan mempertajam ide untuk meyakinkan yang lain.

Kenyataan di lapangan menunjukkan bahwa hasil pembelajaran matematika di Indonesia dalam aspek komunikasi matematik masih rendah. Rendahnya kemampuan komunikasi matematik ditunjukkan dalam studi Rohaeti (2003) bahwa rata-rata kemampuan komunikasi matematik siswa berada dalam kualifikasi kurang. Hal-hal yang menyebabkan rendahnya keaktifan pada setiap diri siswa adalah kurangnya menarik dalam pembelajaran matematika dikelas sehingga siswa menjadi bosan dengan pelajaran matematika, guru kurang memberikan kesempatan kepada siswa yang pasif untuk ikut aktif untuk berpartisipasi dalam pembelajaran matematika, penyampaian materi pembelajaran sangat monoton dan kurang bervariasi, dalam pembelajaran matematika di dalam kelas guru yg sangat berperan aktif sedang siswa pasif. Sehingga mengakibatkan keaktiifan dalam pembelajaran matematika sangat kurang optimal serta suasana pembelajaran yang menyenangkan didalam kelas kurang tampak.

Kemampuan komunikasi matematik siswa dapat ditingkatkan dengan pembelajaran yang menggunakan pendekatan Realistics Mathematics Education (RME), karena pembelajaran yang menggunakan pendekatan Realistic Mathematics Education yaitu pembelajaran yang menghubungkan materi dengan dunia nyata atau kegiatan sehari - hari yang sering dijumpai siswa. Pembelajaran dengan menggunakan pendekatan ini dilaksanakan dengan memanfaatkan realitas dan pengalaman siswa sebagai titik awal pembelajaran.

Menurut Tarigan (Bunga, Isrok'atun \& Julia, 2016), "Pembelajaran matematika realistik merupakan pendekatan yang ditujukan untuk pengembangan pola pikir praktis, logis, kritis, dan jujur dengan berorientasi pada penalaran matematika dalam menyelesaikan masalah". Menurut 
Maulana (Bunga, Isrok'atun \& Julia, 2016), karakteristik pendekatan RME antara lain: 1) Phenomenological Exploration or use context; 2) The use models or bridging by vertical instrument; 3) The use of student own production and construction of student contribution; 4) The interactive character of teaching process or interactivity; dan 5) Intertwining or various learning strand. Karakteristik inilah yang diharapkan muncul dalam proses pembelajaran, sehingga kemampuan koneksi dan komunikasi siswa dapat mengalami peningkatan. Adapun tahapan RME yang akan digunakan dalam penelitian ini merupakan hasil modifikasi dari prinsip-prinsip RME.

Pada saat ini RME mendapat perhatian yang sangat baik di dari beberapa pihak di antaranya guru,siswa,orang tua, dosen LPTK (teacher educations) dan Pemerintah. Beberapa wilayah di Indonesia sudah mecoba menggunakan pendektan RME, khususnya di Jakarta, Surabaya, Bandung, dan Yogyakarta. Sebelum RME diimplementasikan secara luas perlu pemahaman yang mencukupi tentang teori tersebut karena kegagalan dalam inovasi itu bukan karena inovasi itu jelek, tetapi karena kurangnya pemahaman yang menyeluruh dalam inovasi tersebut. Asikin dan Iwan (2013).

\section{METODE}

Penelitian yang dilaksanakan adalah penelitian kuasi eksperimen, Penelitian bertujuan untuk meningkatkan kemampuan komunikasi matematik siswa melalui masalah kontextual pada siswa dalam pembelajaran dalam settingan (RME). Materi yang di pilih adalah segiempat dan segitiga. Subyek yang di pilih adalah siswa MTs Nihayatul Amal yang ada di kota Karawang. Hasil tes diases dengan rubrik penskoran. Untuk menentukan tingkat komunikasi matematik siswa, instrumen yang digunakan adalah hasil modifikasi dari angket yang telah dikembangkan. Hasil yang terkumpul dianalisis untuk menguji hipotesis yang telah dikemukakan. Adapun desain penelitiannya ialah(E. T. Ruseffendi, 2010):

$$
\begin{array}{lll}
\mathrm{O} & \mathrm{X} & \mathrm{O} \\
\mathrm{O} & & \mathrm{O}
\end{array}
$$

Keterangan:

$\mathrm{O}:$ Pretes/Postes kemampuan komunikasi matematik

$\mathrm{X}$ : Pembelajaran matematika dengan pendekatan Realistics Mathematics Education (RME)

--- : sampel ditentukan secara tidak acak

Populasi dalam penelitian ini adalah seluruh siswa MTs Nihayatul Amal. Sekolah tersebut terdiri dari kelas-kelas yang heterogen dan tidak ada kelas unggulan. Sampel dalam penelitian ini adalah dua kelas yang ada di MTs tersebut. Pengambilan sampel dipilih secara tidak acak. Dengan kelas VII A sebagai kelas eksperimen dan VII D sebagai kelas kontrol.

\section{HASIL DAN PEMBAHASAN \\ Hasil}

\section{Analisis Data Pretes}

Pertama yaitu melakukan uji normalitas menggunakan SPSS 21. Melihat tabel shapiro-Wilk sebab penggunaan sampel $<50$ pada tiap kelas. Dengan hipotesis: 
$\mathrm{H}_{0}$ diterima jika nilai Sig. $\geq 0,05$

$\mathrm{H}_{\mathrm{a}}$ ditolak jika Sig. $<0,05$

Keterangan: $\mathrm{H}_{0}$ : sampel berdistribusi normal

$\mathrm{H}_{\mathrm{a}}$ : sampel berdistribusi tidak normal

Dengan hasil sebagai berikut:

Tabel 1. Uji Normalitas Data Pretes

\begin{tabular}{cccc}
\hline \multirow{2}{*}{ Kelas } & \multicolumn{3}{c}{ Shapiro-Wilk } \\
\cline { 2 - 4 } & Statistic & df & Sig. \\
\hline Eksperimen & 0,973 & 26 & 0,700 \\
Kontrol & 0,940 & 28 & 0,111
\end{tabular}

Tabel pengolahan data di atas menunjukan nilai Sig. Kelas eksperimen pada tabel Shapiro-Wilk sebanyak 0,700 (Sig. $\geq 0,05$ ), yang berarti berdistribusi normal. Sementara pada kelas kontrol sebanyak 0,111 (Sig. $\geq 0,05$ ). Karena kedua data tersebut Sig. $\geq 0,05$, maka data berdistribusi normal.

Tabel 2. Uji Homogenitas Data Pretes

\begin{tabular}{cccc}
\hline $\begin{array}{c}\text { Levene } \\
\text { Statistic }\end{array}$ & df1 & df2 & Sig. \\
\hline 2,343 & 1 & 52 & 0,132 \\
\hline
\end{tabular}

Berdasarkan Tabel di atas dapat terlihat kedua data tersebut homogen karena sig. $\geq 0,05$ yaitu 2,343 yang artinya $\mathrm{H}_{\mathrm{o}}$ diterima. Hal ini menunjukan varians kedua kelompok homogen maka dilanjutkan dengan uji perbedaan dua rata-rata dengan uji $t$.

Tabel 3. Uji Dua Rata-Rata Pretes

\begin{tabular}{ccccc}
\hline \multirow{2}{*}{ Kelas } & $\mathbf{N}$ & \multicolumn{2}{c}{$\begin{array}{c}\text { Uji Signifikan Perbedaan Dua } \\
\text { Rata-rata }\end{array}$} & Intrepetasi \\
& & Sig. & Sig. (2-Tailed) & \\
\cline { 1 - 2 } Eksperimen & 26 & 0,132 & 0,044 & Ho Ditolak
\end{tabular}

Berdasarkan hasil output SPSS 21 terlihat bahwa sig. (2-tailed) kedua kelas adalah 0,044 nilai signifikansi ini kurang dari 0,05 artinya $\mathrm{H}_{0}$ ditolak..

\section{Analisis Data Postes}

Berbeda dengan pretes, postes dilaksanakan sesudah pembelajaran menggunakan treatment tertentu berlangsung. Pembelajaran menggunakan pendekatan RME. Hasil olah data postes pada uji normalitas memiliki hipotesis yang sama dengan pretes, yaitu:

$\mathrm{H}_{0}$ diterima jika nilai Sig. $\geq 0,05$

$\mathrm{H}_{\mathrm{a}}$ ditolak jika nilai Sig. $<0,05$

Keterangan: $\mathrm{H}_{0}$ : Sampel berdistribusi normal

$\mathrm{H}_{\mathrm{a}}$ : Sampel berdistribusi tidak normal 
Tabel 4. Uji Normalitas Data Postes

\begin{tabular}{|c|c|c|c|}
\hline \multirow[b]{2}{*}{ Kelas } & \multicolumn{3}{|c|}{ Shapiro-Wilk } \\
\hline & Statistic & Df & Sig. \\
\hline Eksperimen & 0,969 & 26 & 0,606 \\
\hline Kontrol & 0,966 & 28 & 0,476 \\
\hline
\end{tabular}

Tabel pengolahan data di atas menunjukan nilai Sig. Kelas eksperimen pada tabel Shapiro-Wilk sebanyak 0,606 (Sig. $\geq 0,05$ ), yang berarti berdistribusi normal. Sementara pada kelas kontrol sebanyak 0,476 (Sig. $\geq 0,05$ ). Karena kedua data tersebut Sig. $\geq 0,05$, maka data berdistribusi normal. Maka kita tidak perlu melakukan uji Mann-Whitney.

Tabel 5. Uji Homogenitas Data Postes

Levene

\begin{tabular}{crrr} 
Statistic & df1 & \multicolumn{1}{c}{ df2 } & Sig. \\
\hline 3,245 & 1 & 52 & 0,077 \\
\hline
\end{tabular}

Berdasarkan tabel di atas dapat terlihat kedua data tersebut homogen karena sig. $\geq 0,05$ yaitu 3,245 yang artinya $\mathrm{H}_{\mathrm{o}}$ diterima. Hal ini menunjukan varians kedua kelompok homogen maka dilanjutkan dengan uji perbedaan dua rata-rata dengan uji $t$.

Tabel 6. Uji Dua Rata-Rata Pretes

\begin{tabular}{ccccc}
\hline \multirow{2}{*}{ Kelas } & \multirow{N}{*}{} & \multicolumn{2}{c}{$\begin{array}{c}\text { Uji Signifikan Perbedaan Dua } \\
\text { Rata-rata }\end{array}$} & \multirow{2}{*}{ Intrepetasi } \\
\cline { 4 - 4 } & & Sig. & Sig. (2-Tailed) & \\
\hline Eksperimen & 26 & 0,077 & 0,047 & Ho Ditolak \\
\hline Kontrol & 28 & & & \\
\hline
\end{tabular}

Berdasarkan hasil output SPSS 21 terlihat bahwa sig. (2-tailed) kedua kelas adalah 0,047 nilai signifikansi ini lebih dari 0,05 artinya $\mathrm{H}_{0}$ ditolak.

\section{Analisis Data Gain}

Uji Normalitas Gain digunakan untuk melihat peningkatan skor hasil belajar antara sebelum dan sesudah diberikannya tindakan di kelas. Adapun hipotesisnya sebagai berikut:

Sampel berdistribusi normal apabila Sig. $\geq 0,05$

Sampel berdistribusi tidak normal apabila Sig. $<0,05$

Tabel 7. Uji Normalitas Data N-Gain

\begin{tabular}{lrrr}
\hline & \multicolumn{3}{c}{ Shapiro-Wilk } \\
\cline { 2 - 4 } \multicolumn{1}{c}{ Kelas } & Statistic & \multicolumn{1}{c}{ Df } & \multicolumn{1}{c}{ Sig. } \\
\hline Eksperimen &, 967 & 26 &, 556 \\
Kontrol &, 978 & 28 &, 797 \\
\hline
\end{tabular}

Dapat dilihat pada tabel perhitungan IBM SPSS statistics 21 bahwa kedua kelas mendapat Sig. $\geq 0,05$ sehingga kedua sampel tersebut dinyatakan berdistribusi normal. Maka proses 
berikutnya diteruskan uji homogenitas. Adapun hipotesis uji homogenitas adalah sebagi berikut:

Varians kedua sampel dikatakan homogen jika nilai Sig. $\geq 0,05$

Varians kedua sampel dikatakan tidak homogen jika nilai Sig. $<0,05$

Tabel 8. Uji Homogenitas Varians

\begin{tabular}{|c|c|c|c|}
\hline $\begin{array}{l}\text { Levene } \\
\text { Statistic }\end{array}$ & df1 & df2 & Sig. \\
\hline 0,274 & 1 & 52 & 603 \\
\hline
\end{tabular}

Hasil Signifikasi sebesar 0,603 menunjukan bahwa varians kedua sampel homogen (Sig. $\geq$ 0,05). Karena varians kedua sampel homogen maka dapat diteruskan uji $t$ dengan hipotesis sebagai berikut:

Jika Sig. (2-tailed) $\geq 0,05$ maka $\mathrm{H}_{0}$ diterima

Jika Sig. (2-tailed) $<0,05$ maka $\mathrm{H}_{\mathrm{a}}$ ditolak

Sementara kesimpulan yang didapat:

$\mathrm{H}_{0}$ diterima berarti kompetensi murid dari kedua kelas sama.

$\mathrm{H}_{\mathrm{a}}$ ditolak berarti tampak kompetensi akhir yang diraih kedua kelas mengalami perbedaan.

Setelah dilakukan perhitungan ternyata didapat hasil seperti tabel di bawah.

Tabel 9. Uji t Data N-Gain

\begin{tabular}{ccccc}
\hline \multirow{2}{*}{ Kelas } & \multirow{N}{*}{} & \multicolumn{2}{c}{$\begin{array}{c}\text { Uji Signifikan Perbedaan Dua } \\
\text { Rata-rata }\end{array}$} & \multirow{2}{*}{ Intrepetasi } \\
\cline { 3 - 4 } & & Sig. & Sig. (2-Tailed) & \\
\hline Eksperimen & 26 & 0,132 & 0,034 & Ho Ditolak \\
\hline Kontrol & 28 & & & \\
\hline
\end{tabular}

Signifikasi di atas menunjukan Sig. (2-tailed) kurang dari 0,05. Maka $\mathrm{H}_{\mathrm{a}}$ ditolak. Dengan demikian disimpulkam ada perbedaan capaian nilai yang diperoleh kedua sampel. Sehingga terlihat pula disimilaritas kelas eksperimen dengan kelas kontrol yang hanya diberikan pembelajaran biasa.

\section{Pembahasan}

Telah disajikan diperoleh gambaran bahwa kemampuan komunikasi siswa Mts yang disertakan sebagai subyek penelitian masih memprihatinkan. Pemberian sejumlah masalah kontekstual pada pembelajaran matematika dengan setting RME pada siswa tersebut belum respon secara baik. Pada sisi yang lain dapat ditemukan bahwa dengan pemberian masalah kontekstual dalam kemasan yang memenuhi karakteristik RME, sudah terlihat upaya siswa untuk mencetuskan ide orisinalnya.

Sebelum melakukan tindakan khusus kami terlebih dahulu melakukan prestes untuk mengukur kemampuan awal siswa dari kedua kelas. Dilanjutkan dengan penerapan pembelajaran biasa pada kelas kontrol dan pendekatan Realistic Mathematic Education (RME). Materi yang digunakan adalah segitiga dan segiempat. Pada kelas eksperimen siswa dibagi menjadi lima kelompok heterogen. Sistem pengelompokannya sendiri berdasarkan skor awal yang diperoleh. Hal ini agar masing-masing kelompok memiliki kemampuan yang imbang. Lima siswa nilai 
tertinggi dinobatkan sebagai ketua tim. Ketua kelas inilah yang kemudian memotori anggota timnya ketika kegiatan berlangsung.

Broody (1993) mengemukakan (i) gunakan language-experience approach,yakni pendekatan yang didasarkan pada realitas yang meliputi aktivitas: mendengarkan, berbicara, membaca, dan menulis; dalam aktivitas tersebut siswadipandu untuk mengekspresikan reaksi, ide, dan perasaan berkenaan dengan situasi yang ada di kelas, (ii) definisi dan notasi formal harus dibangun melalui situasi informal, (iii) kaitkan istilah-istilah matematika dengan ekspresi yang dijumpai sehari-hari, (iv) penting bagi siswa untuk dapat membandingkan dan membedakan bahasa matematika dengan bahasa sehari-hari. Hal ini diperkuat oleh Artzt (1996) menunjukkan bahwa melalui pembelajaran kooperatif yang dilakukan secara efektif dan melakukan penilaian yang cermat terhadap setiap komunikasi yang terjadi pada setiap aktivitassiswa baik individu maupunkelompok, dapat mengembangkan kemampuan komunikasi.

Setelah pembelajaran berakhir, siswa kedua kelas kembali diminta mengerjakan soal postes untuk mengetahui capain skor yang diperoleh. Berikut diberikan contoh pemikiran orisinal siswa dalam menjawab sebuah masalah kontekstual yang berkaitan dengan segiempat dan segitiga.

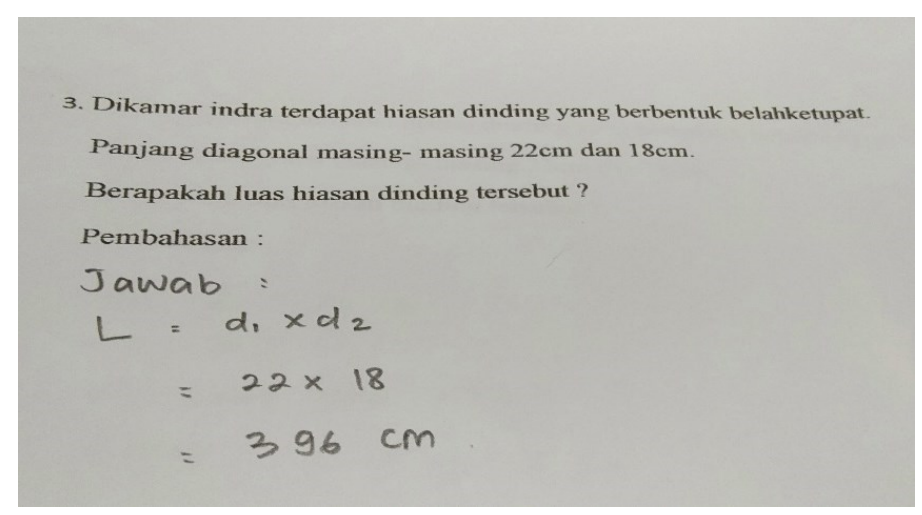

Gambar 1. Jawaban siswa dengan kemampuan komunikasi matematik.

Gambar 1 merupakan contoh hasil yang di kerjakan soal siswa yang memiliki tingkat kemampuan rendah. Rendahnya kemampuan komunikasi matematik pada siswa bisa dipengaruhi oleh pendekatan yang dipilih, strategi yang maupun metode pembelajaran yang digunakan. Hal ini pun sama dengan yang dikemukakan oleh (Afrilianto, 2015)

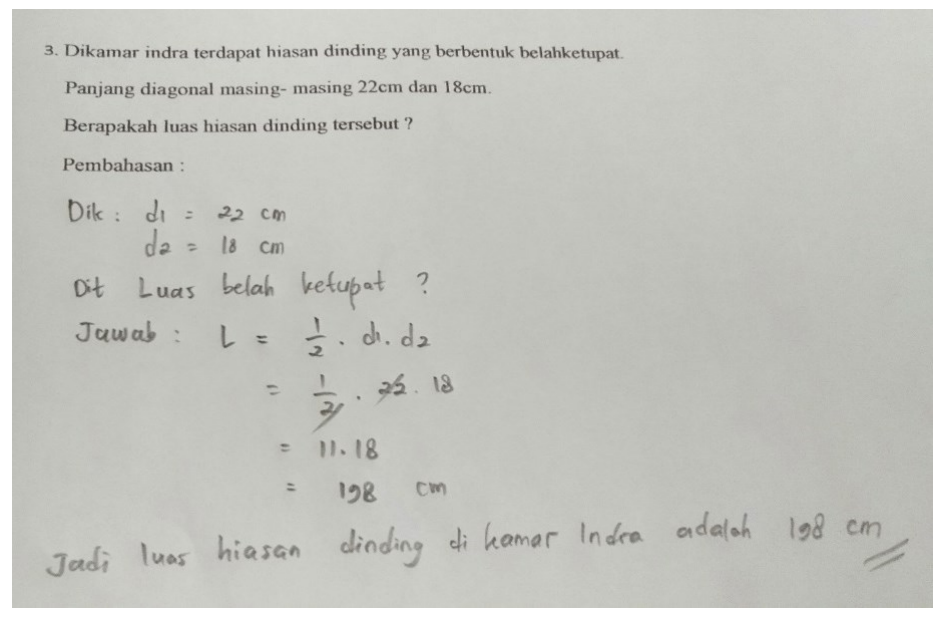

Gambar 2. Jawaban siswa dengan kemampuan komunikasi matematik. 
Gambar 2 merupakan contoh hasil pengerjaan soal siswa yang memiliki tingkat kemampuan tinggi. Telah kita ketahui sebelumnya bahwa meningkatnya kemampuan komunikasi matematik dapat dipengaruhi oleh gurunya, penyajiannya, metodenya,alat peraga/permainannya. Maka sangatlah penting bagi guru untuk memilih pendekatan, strategi ataupun metode untuk diterapkan pada pembelajaran matematika, oleh karena itu diperlukannya pembelajaran yang mudah dipahami siswa misalnya dengan memanfaatkan konteks dalam proses pembelajaran matematika, sehingga mencapai tujuan pendidikan matematika lebih baik. Hal ini diperkuat oleh Asikin et al. (2013) yang mengemukakan tentang pendekatan Realistic Mathematics Education (RME) lebih unngul daripada pendekatan konvensional.

\section{KESIMPULAN}

Berdasarkan paparan di atas, kami menyimpulkan bahwa kemapuan komunikasi matematik dikelas yang menerpkan pendekatan Realistic Mathematic Education (RME) lebih unggul daripada yang menggunakan pembelajaran konvensional. Adapun kekurangan serta kelebihan yang tampak dilapangan yaitu:

Kelebihan: hasil peninjauan dikelas menunjukan bahwa Realistic Mathematic Education (RME) membuat siswa lebih interaktif dalam diskusi terutama ketika melakukan tanya jawab kepada teman satu kelompoknya sendiri dbawah pengawasan serta bimbingan guru.

Kekurangan: pada penerapannya membutuhkan persiapan yang lumayan memakan waktu.

\section{DAFTAR PUSTAKA}

Afrilianto, M. (2015). Pengaruh Pendekatan Model-Eliciting Activies Terhadap Kemampuan Komunikasi Matematik Siswa SMP. Jurnal Ilmiah UPT P2M STKIP Siliwangi, 2(1), 128136.

Artzt, A.F. (1996).«Developing Problem Solving Behaviors by Assessing Communication In Cooperative Learning". In P.C Elliott, and M.J. Kenney (Eds.). 1996 Yearbook

Asikin, Mohammad, dan Junaedi Iwan. 2013. "Kemampuan Komunikasi Matematika Siswa SMP dalam Setting Pembelajaran RME (Realistic Mathematics Education)." "Kemampuan Komunikasi Matematika Siswa SMP dalam Setting Pembelajaran RME (Realistic Mathematics Education) 2 (1).

Baroody. A.J. 1993.Problem Solving, Reasoning, and Communicating.New York: Macmillan Publishing.

Bunga, N., Isrok'atun, J. (2015). Pendekatan Realistic Mathematics Education untuk Meningkatkan Kemampuan Koneksi dan Komunikasi Matematis Siswa. Jurnal Pena Ilmiah, 1(1), 441-450

Fauzan, Ahmad, dan Yerizon Yerizon. 2013. "Pengaruh Pendekatan RME dan Kemandirian Belajar Terhadap Kemamampuan Matematis Siswa.” Prosiding SEMIRATA 1 (1).

Rohaeti, E. E. (2003). Pembelajaran Matematika dengan Menggunakan Metode Improve untuk Meningkatkan Pemahaman dan Kemampuan Komunikasi Matematik Siswa SLTP (Doctoral dissertation, Tesis PPS UPI. Bandung: tidak diterbitkan). 
Rohaeti, E. E. (2011). Transformasi Budaya melalui Pembelajaran Matematika Bermakna di Sekolah. Jurnal Pengajaran MIPA, 16(1), 139-147

Ruseffendi, E. T. (2009). Dasar-dasar penelitian pendidikan dan bidang non-eksakta lainnya. Bandung: Tarsito.

Sufi, L. F. (2016). Meningkatkan Kemampuan Komunikasi Matematis Siswa Melalui Model Pembelajaran Problem Based Learning. 
292 Anggraini, Pertiwi \& Afrilianto, Penenerapan Pendekatan Realistics Mathematics ..... 